\title{
Green synthesis of copper oxide nanoparticles using Citrus limetta (sweet lime) peel waste
}

\author{
Valantena Noory ${ }^{1, *}$ and Rahela Saeedy ${ }^{2}$ \\ ${ }^{1}$ Department of General Inorganic Chemistry, Chemical Engineering Faculty, Jawzjan University, Afghanistan. \\ ${ }^{2}$ Department of Inorganic Production, Chemical Engineering Faculty, Jawzjan University, Afghanistan.
}

Magna Scientia Advanced Biology and Pharmacy, 2021, 02(02), 010-013

Publication history: Received on 07 April 2021; revised on 10 May 2021; accepted on 12 May 2021

Article DOI: https://doi.org/10.30574/msabp.2021.2.2.0020

\begin{abstract}
The fast development of nanomaterials in the quest for green, eco-friendly routes for new products often culminates in the utilization plant biomasses for the synthesis of sustainable nanoparticles. In this study, an eco-friendly, and costeffective method has been established for the synthesis of copper oxide nanoparticles (CuONPs) using sweet lime peel extract. The synthesized nanoparticles were characterized using UV-visible spectroscopy and scanning electron microscopy. The CuONPs formed were almost agglomerated spherical in shape with a discrete rough appearance. The particle sizes measured from scanning electron microscopy (SEM) ranged from 90-175 $\mathrm{nm}$. The results revealed the cost effective, time saving, renewable, green and sustainable route for CuONPs to be formed. This may open a new avenue of methods to reuse sweet lime peels.
\end{abstract}

Keywords: Fruit wastes; Nanoparticles; Copper oxide nanoparticlesgreen synthesis; Green chemistry

\section{Introduction}

Green chemistry is an emphasized area of research and requires some additional efforts for the implementation of sustainable methods in order to achieve the desirable products as well as to minimize and further eliminate the waste materials produced [1,2]. Conventionally, variable methods have been developed till date such as physical methods including thermal decomposition [3], evaporation-condensation or laser ablation [4] and chemical methods involving reduction of solution to form metal clusters [5], photochemical reactions in reverse micelles [6], sonochemical [7], electrochemical [8], radiation assisted [9] and via microwave assisted techniques [10]. As these methods utilized precarious and environmentally lethal chemicals, required high energy, or low material conversions as well as tedious purification, hence arose different issues while going through these processes mainly regarding stabilization and aggregation of nanoparticles [11].

Most of these methods are expensive, have high-energy requirements, involve the utilization of hazardous chemicals, and some of them produce substantial amounts of by-products. Synthesis of nanoparticles by using biological methods is important because biological methods are safe, low cost, environment friendly and can be used in large scale synthesis as an alternative to chemical and physical methods. In this context, the "green biosynthesis" of NPs offers advantages over conventional synthetic methods that include the use of environmental friendly solvents and nontoxic reducing agents which are extracted from plants, bacteria and fungi that promote an enhanced NPs stability [12]. As per green synthetic strategy, renewable as well as non-toxic materials should be used. The use of fruit waste as source of reducing chemicals may be of considerable economic benefits and has become increasingly attractive [13]. Different wastes have been used for the synthesis of AgNPs, such as banana peel [14], papaya peel [15], tea wastes, sugarcane bagasse [16] and orange peel. Citrus fruits are widely cultivated in tropical and subtropical regions in dried and arid condition. Citrus

${ }^{*}$ Corresponding author: Valantena Noory

Lecturer in Department of General Inorganic Chemistry, Chemical Engineering Faculty, Jawzjan University, Afghanistan. 
limetta is also known as sweet lime having a large number of benefits regarding health issues, like scurvy, peptic ulcer, diabetes, skin, hair, etc. In the present study, it is proposed to synthesize copper oxide nanoparticles by using the biowaste viz. sweet lime peels.

\section{Material and methods}

\subsection{Preparation of sweet lime peel extract}

The fresh peels of sweet lime were washed with deionized water to eliminate dust and organic contaminants. Approximately $100 \mathrm{~g}$ of small slices of sweet lime peels were added to a $500 \mathrm{~mL}$ beaker filled with $150 \mathrm{~mL}$ of deionized water and heated at $70-80^{\circ} \mathrm{C}$ for $20 \mathrm{~min}$. A light yellow-colored solution was formed during the heating period. Upon cooling, the light yellow-colored solution was filtered through vacuum filtration at room temperature. The filtrate (extract) was collected in a $100 \mathrm{~mL}$ beaker which was used directly for the synthesis of CuONPs.

\subsection{Synthesis of copper oxide nanoparticles}

The amount of sweet lime peel extract and the metal salt solution needed to synthesize the nanoparticles were optimized by adding various amount of extract to $\mathrm{CuSO}_{4}$ solution. After the elaborate process of optimization, it was found that equal amount of extract and $0.1 \mathrm{M} \mathrm{CuSO}_{4}$ solution was ideal to prepare $\mathrm{CuO} / \mathrm{Cu}_{2} \mathrm{O}$ nanoparticles. The $\mathrm{CuO} / \mathrm{Cu}_{2} \mathrm{O}$ nanoparticles were prepared by mixing $100 \mathrm{~mL}$ of peel extract with $100 \mathrm{~mL}$ of $0.1 \mathrm{M} \mathrm{CuSO}_{4} \mathrm{Solution}_{\text {. The }}$ reducing agents present in the extract were responsible for the formation of copper oxide nanoparticles. When the extract (brown in colour) was mixed with $\mathrm{CuSO}_{4}$ Solution (blue in colour), the resulting solution became green. Then 5 $\mathrm{mL}$ of $1 \mathrm{M} \mathrm{NaOH}$ solution was added to the above solution as the precipitating agent, $\mathrm{Cu}_{2} \mathrm{O} / \mathrm{CuO}$ nanoparticles started to precipitate slowly and it was filtered and dried. The constituents in the extracts itself act as a reducing and capping agent to prevent the agglomeration of nanoparticles.

\subsection{Detection methods}

Optical absorption spectra of the synthesized nanoparticles were taken in the UV-visible double beam spectrophotometer 2201, Systronics using a quartz cuvette of $1 \mathrm{~cm}$ path length. The detailed morphological and size analyses of green-synthesized CuONPs were studied using electron microscopy (SEM).

\section{Results and discussion}

\subsection{UV-visible spectrum of $\mathrm{CuO} / \mathrm{Cu}_{2} \mathrm{O}$ nanoparticles}

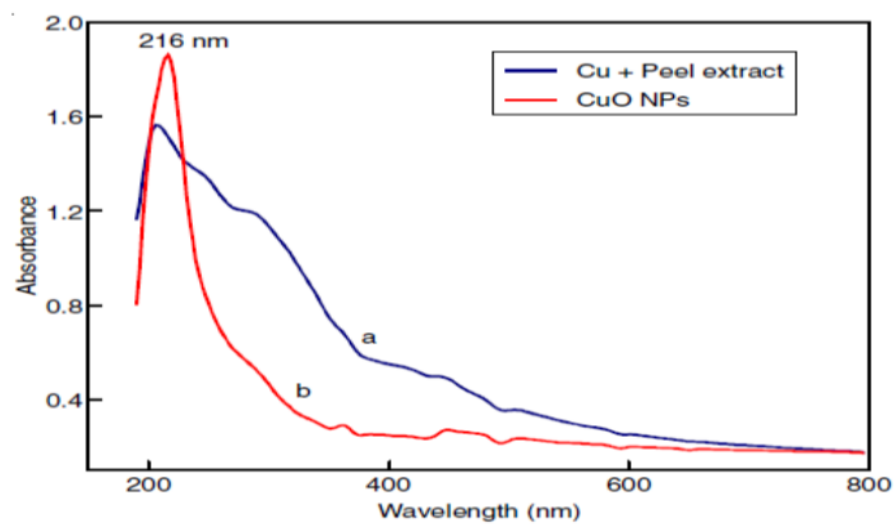

Figure 1UV-visible spectra of (a) mixture of extract and $\mathrm{CuSO}_{4}$ solution (blue colour); (b) Colloidal CuO nanoparticles solution after the addition of base.

The UV-visible spectrum of $\mathrm{CuO}$ nanoparticles solution is shown in Fig. 1. When the pomegranate peel extract was mixed with CuSO4, the UV-visible spectrum was broad with a band at $206 \mathrm{~nm}$ (CuO nanoparticles) and two small humps are shown in 246 and $283 \mathrm{~nm}$ but after the addition of $\mathrm{NaOH}$, the concentration of nanoparticles was increased as evidenced by a sharp peak at $216 \mathrm{~nm}$. 
The detailed morphological and size analyses of green-synthesized CuONPs were studied using electron microscopy (SEM) and the results are shown in Fig. 2. Based on Figure, the CuONPs formed were almost agglomerated spherical in shape with a discrete rough appearance. The particle sizes measured from SEM ranged from 90-175 nm.

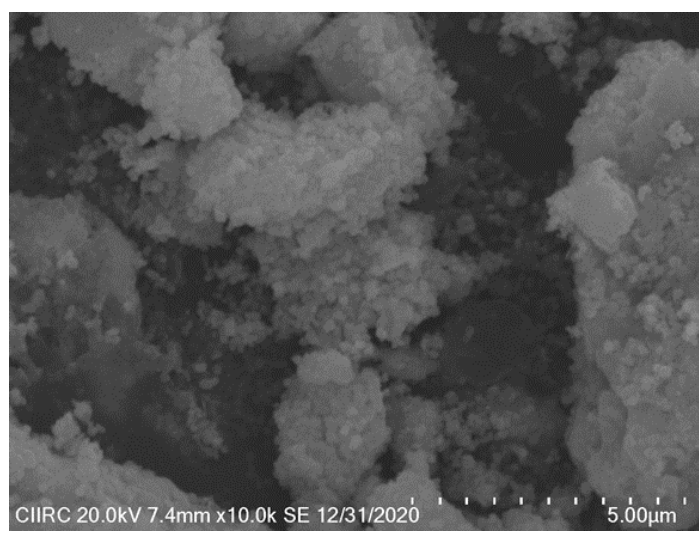

Figure 2 SEM analysis of sweet lime peel mediated $\mathrm{CuO}$ nanoparticles

Plants extracts have added advantage as they take less time to reduce the metal ions. The main reason for considering the natural plant-based extracts for synthesizing NPs is the use of green chemistry in their synthesis. The primary benefit of using green chemistry for synthesizing NPs is that it allows the selection of an eco-friendly reducing agent, solvent medium and non-toxic material for stabilization of NPs [17]. Copper oxide $\left(\mathrm{Cu}_{2} \mathrm{O}\right)$ is claimed to be a transition metal oxide having narrow bandgap, i.e. $2.0 \mathrm{eV}$ and shows distinct features like significant electrochemical activity, improved redox potential, high specific surface area and incomparable stability in solutions. It is the second choice of researchers working in the field of nanotechnology after the noble metal nanoparticles, owing to its propitious application in different subjects like antifouling coatings, biocidal agents, catalysis, sensors/biosensors, electrochemistry and energy storage [18]. Copper oxide (CuO) nanoparticles find wide applications in agricultural, industrial engineering and technological field. Herein $\mathrm{CuO}$ NPs were synthesized in an eco-friendly manner using the aqueous extract of sweet lime peel waste.

\section{Conclusion}

In summary, a green and cost-effective method for the synthesis of copper oxide nanoparticles using the waste sweet lime peel which focused on the utilization of waste was demonstrated. This study also reported the cost effective, time saving, renewable, green and sustainable route for CuONPs to be formed. This may open a new avenue of methods to reuse sweet lime peels.

\section{Compliance with ethical standards}

\section{Acknowledgments}

The authors acknowledge the support from Jawzjan University.

\section{Disclosure of conflict of interest}

The authors declare that there is no conflict of interest.

\section{References}

[1] Anastas PT, Warner JC. Green Chemistry: Theory and Practice. Oxford University Press, New York. 1998.640.

[2] Raveendran P, Fu J, Wallen SL, Hill C, Carolina N. Completely green synthesis and stabilization of metal nanoparticles. J. Am. Chem. Soc. 2003; 13940- 13941.

[3] Esumi K, Tano T, Torigoe K, Meguro K. Preparation and characterization of bimetallic Pd-Cu colloids by thermal decomposition of their acetate compounds in organic solvents. Chem. Mater. 1990; 2: 564-567. 
[4] Scaramuzza S, Zerbetto M, Amendola V. Synthesis of gold nanoparticles in liquid environment by laser ablation with geometrically confined configurations: insights to improve size control and productivity. J. Phys. Chem. C. 2016; 120: 9453-9463.

[5] Goia DV, Matijevic E. Preparation of monodispersed metal particles. New J. Chem. 1998; 22(11): 1203-1215.

[6] Taleb A, Petit C, Pileni MP. Synthesis of highly monodisperse silver nanoparticles from AOT reverse micelles:a way to 2D and 3D self-organization. Chem. Mater. 1997; 9: 950-959.

[7] Zhu C, Feng R, Zhao, Y. Sonochemical effect of a bifrequency irradiation. Chin. Sci. Bull. 2000; 45: 142-145 (2000).

[8] Rodríguez-Sánchez L, Blanco MC, López-Quintela MA. Electrochemical synthesis of silver nanoparticles. J. Phys. Chem. B. 2000; 104: 9683-9688

[9] Henglein A. Reduction of $\mathrm{Ag}(\mathrm{CN}) 2^{-}$on silver and platinum colloidal nanoparticles. Langmuir, 2001;, 17: 23292334

[10] Chen D, Zhang Y, Chen B, Kang Z. Coupling effect of microwave and mechanical forces during the synthesis of ferrite nanoparticles by microwave- assisted ball milling. Ind. Eng. Chem. Res. 2013; 52: 14179-14184.

[11] Iravani S, Korbekandi H, Mirmohammadi SV, Zolfaghari B. Synthesis of silver nanoparticles: chemical, physical and biological methods. Res. Pharm. Sci. 2014; 9(6): 385-406.

[12] Li D, Liu Z, Yuan Y, Liu Y, Niu F. Green synthesis of gallic acid-coated silver nanoparticles with high antimicrobial activity and low cytotoxicity to normal cells. Process Biochemistry. 2015; 50: 357-366.

[13] Kaderides K, Goula AM. Development and characterization of a new encapsulating agent from orange juice byproducts. Food Research International. 2017; 100: 612-622.

[14] Ibrahim HMM. Green synthesis and characterization of silver nanoparticles using banana peel extract and their antimicrobial activity against representative microorganisms. Journal of Radiation Research and Applied Sciences, 2015; 8: 265-275

[15] Balavijayalakshmi J, Ramalakshmi V. Carica papaya peel mediated synthesis of silver nanoparticles and its antibacterial activity against human pathogens. Journal of Applied Research and Technology. 2017; 15(5): 413422.

[16] Qing W, Chen K, Wang Y, Liu X, Lu M. Green synthesis of silver nanoparticles by waste tea extract and degradation of organic dye in the absence and presence of $\mathrm{H}_{2} \mathrm{O}_{2}$. Applied Surface Science. 2017; 423: 1019-1024.

[17] Kumar H, Bhardwaj K, Kuca K, Kalia A, Nepovimova E, Verma R, Kumar D. Flower-based greensynthesis of metallic nanoparticles: Applications beyond fragrance. Nanomaterials. 2020; 10: 766.

[18] Verma N, Kumar N. Synthesis and biomedical applications of copper oxide nanoparticles: An expanding horizon. ACS Biomater. Sci. Eng. 2019: 5: 1170-1188. 